\title{
El dibujo manual y digital como generador de ideas en el proyecto arquitectónico contemporáneo
}

\author{
Manual and digital drawing as generator of ideas in the contemporary architectural project
}

\section{Javier Alonso Bohórquez-Rueda}

Universidad de Boyacá, Sogamoso (Colombia)

Facultad de Arquitectura, Diseño y Urbanismo

Centro de Investigaciones para el Desarrollo (Cipade)

Magda Paola Montañez-Moreno

Universidad de Boyacá, Sogamoso (Colombia)

Facultad de Arquitectura, Diseño y Urbanismo

Centro de Investigaciones para el Desarrollo (Cipade)

Wilmer Leonardo Sánchez-Ávila

Universidad de Boyacá, Sogamoso (Colombia)

Facultad de Arquitectura, Diseño y Urbanismo

Centro de Investigaciones para el Desarrollo (Cipade)

\author{
Javier Alonso Bohórquez-Rueda \\ Arquitecto, Universidad Católica de Colombia. (Colombia) \\ Doctor en Educación, Universidad de La Salle. San José de Costa Rica (Costa \\ Rica) \\ Magíster en Creatividad e Innovación, Universidad Fernando Pessoa (Portugal) \\ https://scholar.google.com/citations?user=MAEi_N4AAAAJ\&hl=es \\ (iD) https://orcid.org/0000-0003-247I-3534 \\ javbohorquez@uniboyaca.edu.co \\ Magda Paola Montañez-Moreno \\ Diseñadora Industrial, Universidad Pedagógica y Tecnológica de Colombia (Colom- \\ bia) \\ Especialista en Gerencia en Multimedia, Universidad Santo Tomás, (Colombia) \\ https://scholar.google.es/citations?hl=es\&pli= I \&user=sPUVbOAAAAA \\ (iD) https://orcid.org/0000-0002-937I-8972 \\ mpmontanez@uniboyaca.edu.co \\ Wilmer Leonardo Sánchez-Ávila \\ Arquitecto con énfasis en Urbanismo, Universidad de Boyacá (Colombia) \\ Especialista en Salud Ocupacional y Riesgos Laborales, Universidad Pedagógica y \\ Tecnológica de Colombia (Colombia) \\ https://scholar.google.es/citations?hl=es\&user=TWsivQUAAAA \\ iD https://orcid.org/0000-0002-7804-990X \\ wlsanchez@uniboyaca.edu.co
}

Bohórquez-Rueda, J. A., Montañez-Moreno, M. P., \& Sánchez-Ávila, W. L. (2019). El dibujo manual y digital como generador de ideas en el proyecto arquitectónico contemporáneo. Revista de Arquitectura (Bogotá), 22(I). 107-II7 https://doi.org//0.147/8/RevArq.2020.2660

\section{Resumen}

El dibujo como medio de concepción ideacional es un factor clave para el proyecto arquitectónico y su estudio incide de manera directa en entornos educativos. En consecuencia, en el presente artículo de revisión, se realizó la indagación, organización, estructuración y análisis de documentos científicos y académicos publicados preferentemente con posterioridad al 2000 y disponibles en bases de datos. A partir de esto, se realizó una aproximación conceptual, con el propósito de examinar y clasificar las posiciones argumentativas. La información recopilada se clasificó así: I.) Aportes del dibujo para el aprendizaje, los procesos creativos y el pensamiento de los diseñadores en términos de generación de ideas proyectuales. 2.) Función que desempeña la relación existente entre mano, ojo y mente con respecto a la generación de ideas mediante el acto de dibujar, y 3.) Incidencia en el entorno proyectual en relación con, si el dibujo es hecho de manera manual, digital o combinado. A modo de conclusión se menciona la conveniencia de promover la combinación del dibujo manual y el digital para dar respuesta a las nociones emergentes de la forma y la transmisión de la información acordes a los nuevos modos de representación.

Palabras clave: dibujo arquitectónico; tecnologías digitales; investigación creación; pensamiento creativo; representación arquitectónica; técnicas del dibujo; tecnologías de la información y la comunicación (TIC)

\begin{abstract}
Drawing as a way of ideational conception is a key factor for the architectural project and its study directly affects educational environments. Consequently, in this review article, the investigation, organization, structuring and analysis of scientific and academic documents published preferably after 2000 and available in databases was carried out. From this, a conceptual approach was carried out, with the purpose of examining and classifying argumentative positions. The information collected was classified as follows: I) Contributions of drawing to learning, creative processes and thinking of designers in terms of generating project ideas. 2) Function played by the relationship between hand, eye and mind with respect to the generation of ideas through the act of drawing, and 3) Impact on the project environment in relation to whether drawing is done manually, digitally or in a combined manner. In conclusion, the convenience of promoting the combination of manual and digital drawing to respond to emerging notions of the form and transmission of information according to the new modes of representation is mentioned.
\end{abstract}

Keywords: architectural drawing; digital technologies; creation research; creative thinking; architectural representation; drawing techniques; Information technologies and communication (ICT)

\section{Introducción}

Este trabajo hace parte de la investigación denominada "Fortalecimiento de la Expresión Gráfica Análoga de los estudiantes de Arquitectura de la Universidad de Boyacá", que está adscrita, a su vez, a la línea de investigación: Innovación en hábitat, patrimonio y diseño, de la Facultad de Arquitectura, Diseño y urbanismo, y del Centro de Investigaciones para el Desarrollo (Cipade).

Como objetivo, se propone introducir una reestructuración en los procesos de enseñanza-aprendizaje del diseño arquitectónico, en lo referente a la gestación y la representación gráfica en la ideación proyectual, combinando las capacidades expresivas análogas con herramientas tecnológicas digitales. En esta misma problemática se plantearon hipótesis que involucran la conveniencia de incorporar a través del acto de dibujar, cualidades sensitivas no visuales como las táctiles y las gestuales, estimulando tanto las competencias emocionales y relacionales como el potencial innovador y creativo en los estudiantes relacionados.

En el presente artículo de revisión se busca hacer una categorización y una clasificación de fuentes relacionadas con el dibujo manual y digital como generador de ideas en el proyecto arquitectónico contemporáneo, considerando el grado de implicación según se recurra al dibujo manual, al digital, o a la combinación de ambos, ante la ambivalencia que se detecta en este sentido desde la introducción de la digitalización en la representación en diseño, y las incidencias que 
ello implica en aspectos como el aprendizaje y el pensamiento creativo para la ideación proyectual, y su relevancia en los ámbitos académico y pedagógico de las instituciones que imparten la formación en esta disciplina en el contexto local.

Al revisar el papel que juega el dibujo en la ideación proyectual en arquitectura se hace necesario identificar algunos aspectos conexos, tales como los procesos creativos desde un entorno indagatorio; las implicaciones comunicativas desde principios de abstracción de la forma dentro de la imagen; la función que desempeña la relación mano, ojo y mente, como expresión corporal del pensamiento; y los aspectos que estos componentes desencadenan para el conocimiento y el aprendizaje de los diseñadores en proceso de formación, o ya graduados.

A partir de estos aspectos se realiza una aproximación desde aspectos teórico-conceptuales revisando diversos autores, que permita identificar los elementos implícitos, a través de la revisión de papers.

Finalmente, se analizan los aspectos clave relacionados, a fin de elaborar un diagnóstico pertinente que permita identificar los factores de relevancia que intervienen en los procesos de generación ideacional de los proyectos de arquitectura, y de esta forma, generar sugerencias para los procesos de enseñanza-aprendizaje de las facultades de arquitectura del área de influencia estudiada.

\section{Metodología}

Este trabajo comprende una investigación teórico-descriptiva constituida a partir de los resultados obtenidos en una búsqueda documental cuyo procedimiento incluyó la indagación, organización, estructuración y análisis de un grupo de textos, documentos científicos y académicos publicados preferentemente con posterioridad al 2000. Igualmente, se determinó delimitar la búsqueda a países de la región latinoamericana incluyendo España, debido al interés que suscita para la institución patrocinadora de este trabajo, para la región y específicamente para este caso, la manera como se asumen los nuevos paradigmas y cambios que incorporan la tecnología y su implicación en la concepción y generación de ideas en el proyecto arquitectónico contemporáneo local.

Las unidades de análisis fueron todos aquellos documentos que abordaran, resaltaran o analizaran la temática concerniente a las incidencias que el dibujo juega en la ideación proyectual en arquitectura, más allá de su función como representación.

La primera fase del proyecto incluyó la búsqueda de investigaciones y experiencias relacionadas con los escenarios descritos, a partir de lo cual se crearon unas categorías iniciales que guiaron la búsqueda:

1. Aspectos que el dibujo aporta para el aprendizaje, los procesos creativos y el pensamiento de los diseñadores, en términos de generación de ideas proyectuales.
2. La función que desempeña la relación mano, ojo y mente en relación con la generación de ideas mediante el acto de dibujar.

3. La incidencia en el entorno proyectual, teniendo presente si el dibujo se realiza de manera manual, a través de tecnologías digitales o de manera combinada.

La segunda fase del proyecto se ocupó del análisis de cada una de las categorías planteadas, de aspectos afines y de diferencias entre los documentos seleccionados, mediante un proceso de comparación permanente. Finalmente, se formularon algunas hipótesis y conclusiones y se realizaron algunas recomendaciones.

\section{Resultados}

En referencia al primer factor establecido para la investigación se encontró, como se puede apreciar en la tabla 1, que los autores revisados vinculan el dibujo con respecto al aprendizaje, la creatividad y el pensamiento, como una intencionalidad manifiesta en conceptos y sensaciones múltiples que relativizan el resultado a la experiencia personal de cada diseñador y/o estudiante. De esta manera, se realizó una clasificación de carácter cualitativo que sintetizara en una palabra o frase el pensamiento de cada autor en relación con la temática propuesta.

A pesar del carácter subjetivo que implica la diversidad de conceptos revisados, lo cual presentó una dificultad para la aplicación de metodologías significativas para el modelo científico, se pudo establecer que la multiplicidad de opiniones recogen argumentos consistentes con la hipótesis inicial, que señala la factibilidad de involucrar factores de orden emocional y relacional que logren estimular el potencial innovador y creativo en las estrategias formativas, relacionados con la manera de concebir e idear la proyectación arquitectónica a través de la expresión gráfica, más allá de su función meramente representativa. El sinnúmero de adjetivos reunidos en dicha clasificación involucran tópicos que relacionan la superación a partir del autoaprendizaje y la autonomía, así como la implicación de procesos complejos de pensamiento, transformación e imaginación en cualquier sujeto implicado en una exploración de ideas de diseño, generadas a partir del dibujo, sin importar que estos sean realizados manual o digitalmente. En relación con el segundo factor planteado, de igual manera se estableció un concepto específico por cada autor (tabla 2), en cuanto a la función que mediante el acto de dibujar se manifiesta en la relación entre mano, ojo y mente. En este caso también se pudo corroborar la hipótesis inicial, que señala la relevancia de incorporar a través del dibujo cualidades sensitivas no visuales, como las táctiles y las gestuales, en procesos de generación de ideas de diseño, a partir del dibujo. 
1.

Aportes del dibujo para el aprendizaje, los procesos creativos y el pensamiento de los diseñadores en términos de generación de ideas proyectuales
Kosma (2016).

Granero Martín (2017).

Rodrígues (2011).

Bru (2016).

Seguí de la Riva (2003).

Kahn (citado en Castellanos Gómez \& Domingo

Calabuig, 2013).

Marchant (2016).

Raposo, Grau et al. (2018).

Hidalgo (2016).

Gombrich (1994).

Focillon (2006).

Edwards (1988).

Tanoue, Castral y Lancha (2011).

Flores (2011).

Delgado Yanes y Redondo Domínguez. (2006).

Niño (2006).

Puebla Pons (2006).

Siza (2003).

Pride (citado en Faure Walker, 2008).
Acción-gesto

Abstracción

Comunicación

Acumulación

Tanteo configurado

Persuasión

Croquis de observación

Conocimiento-conciencia

Repetición-demostración

Mentalidad del autor

Permanencia

Metáfora del autor

Aprendizaje corporal

El dibujo como lenguaje

La realidad aun no construida

El dibujo como construcción de imagen y no como trazo

Estrategia de emprendimiento, curiosidad y exploración

Aprensión del lugar y forma de aprendizaje

Dibujo como aprendizaje y estudio fenomenológico como expansión

(A) Tabla 1. Ideas principales según autores revisados (factor 1 ).

Fuente: elaboración propia (2019).

\section{Factor}

2. Función que desempeña la relación entre mano, ojo y mente en relación con la generación de ideas mediante el acto de dibujar

\section{Pallasmaa (2010 y 2012).}

Sennett (2009).

Wilson (2002).

Trachana (2012).

Heidegger (2005).

Rossado Espinoza (2017).

Campo (2010).

Llopis Verdú, Giménez Ribera y Barros da Rocha e Costa (2013).

Machado González (2016).

Alba Dorado (2013).

Navarro (2007).

Bolívar Montesa (2018).

Ocampo Hurtado (2014).

Vidaurre et al. (1979).

Tanoue, Castral y Lancha (2011).
Contacto háptico, objetual y espacial

Coordinación, tacto, visión, pensamiento

Equivalencia entre mente, mano y aprendizaje

Conocimiento a través de la visión y la percepción táctil

Relación mano-pensamiento

Calidez humana y trazo a mano

Pensar con las manos y construir con la cabeza

Asociación íntima entre percepción y forma a través de las manos

Acto generativo y transformativo, manual y perceptivo

Información, simultánea en la proyectación

Construcción con la mano, y reacciones íntimas y orgánicas

Organización y estructuración bajo el relato de la mirada

Experiencias físicas como inferencia de ideas

Ocasión, traducción y lugar

Conexión, cuerpo, mente y expresión 


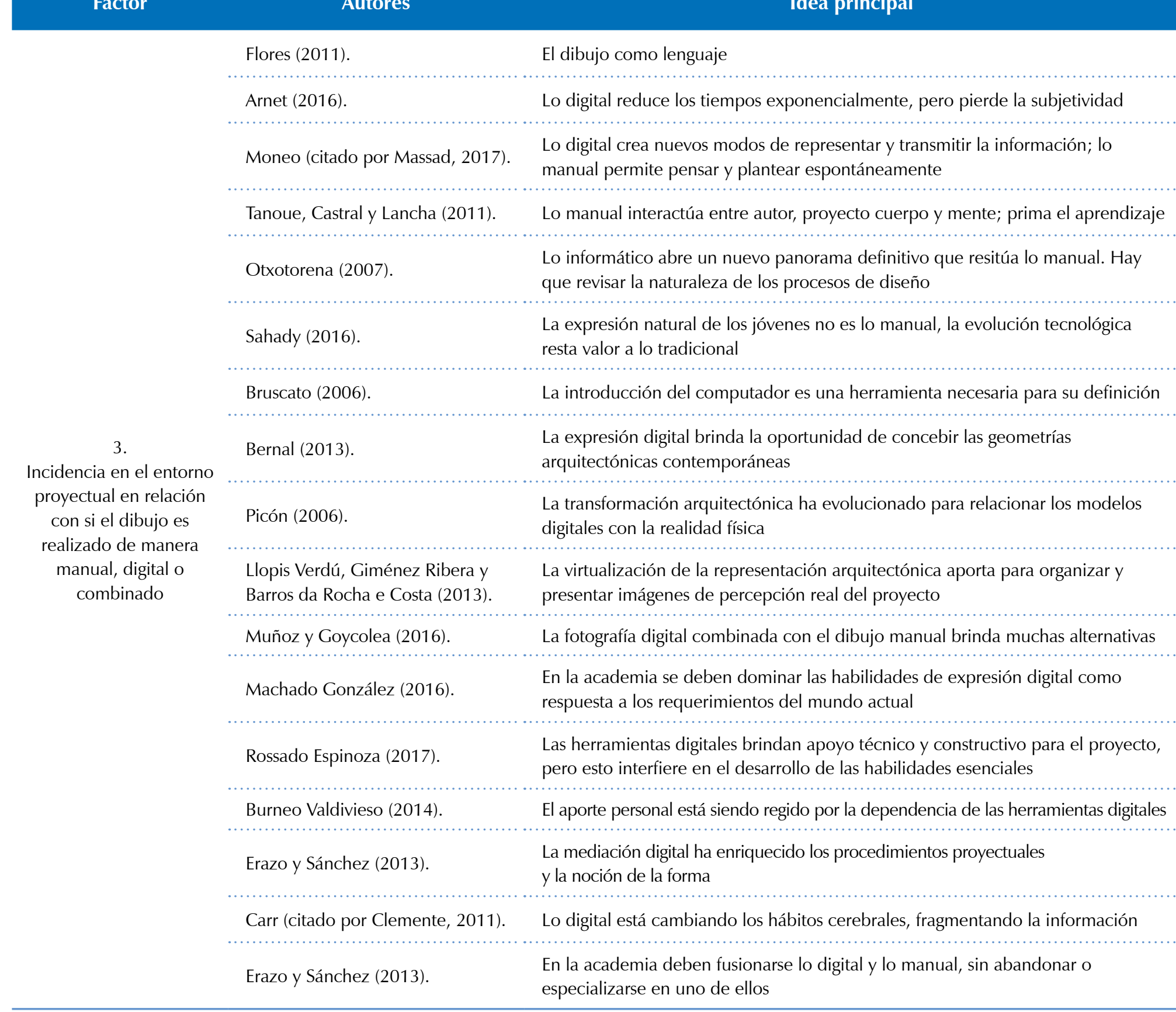

(A) Tabla 3. Ideas principales según autores revisados (factor 3).

Fuente: elaboración propia (2019).
De idéntica manera, se procedió a extractar una idea representativa por cada uno de los autores revisados, que contuviese un concepto que identificara la incidencia en el entorno proyectual que implica el dibujo según si se realice de manera manual, digital o combinada (tabla 3 ). En síntesis, el resultado para este objetivo específico de la investigación se inclina a favorecer una postura según la cual es necesario complementar el dibujo manual o tradicional, a partir de la incorporación de herramientas y enfoques novedosos emergentes tanto en el ámbito de la elaboración como en el de ideación, desde la implementación de técnicas digitales de expresión gráfica.

En la figura 1 se sintetiza porcentualmente la relevancia que para los autores revisados desempeña el dibujo en un entorno proyectual, según se haga mediante técnicas manuales, digitales o combinadas. A pesar de que pareciera que en la actualidad la expresión digital predominara en los procesos de ideación en diseño, la mayoría de los autores no desestiman la importancia del dibujo manual; por ello, predomina dicha opción en este análisis. Para muchos, no existe un predominio de un tipo de expresión sobre otro; de ahí el alto porcentaje obtenido en la opción de indeterminado. Mientras, en las opciones donde se plantea la combinación de ambas técnicas se dividen las opiniones. Finalmente, aunque la opción de técnicas de expresión digital aparece ocupando una posición discreta, para la mayoría de los autores, en un futuro cercano esta pasará a predominar, debido a la acelerada globalización y al predominio de las nuevas tecnologías.

\section{Discusión}

Por tratarse de un artículo de revisión, esta discusión se presenta de manera comparativa, aludiendo a los aspectos teórico-conceptuales abordados por los autores revisados. Para ello, dichos aspectos se han agrupado temáticamente en cuatro títulos relacionados con los factores previamente considerados. 


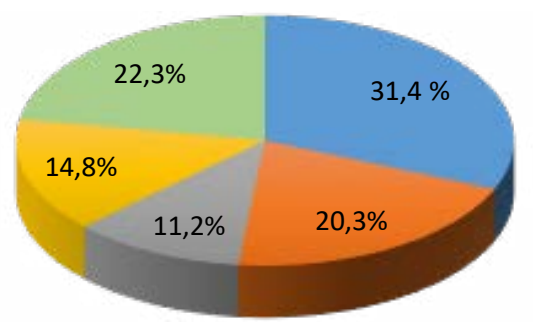

Dibujo manual

Expresión digital

Combinado con preferencia digital

Combinado con preferencia manual

Otros

A Figura 1. Incidencia de las técnicas de expresión en arquitectura.

Fuente: elaboración propia (2019). CC BY.
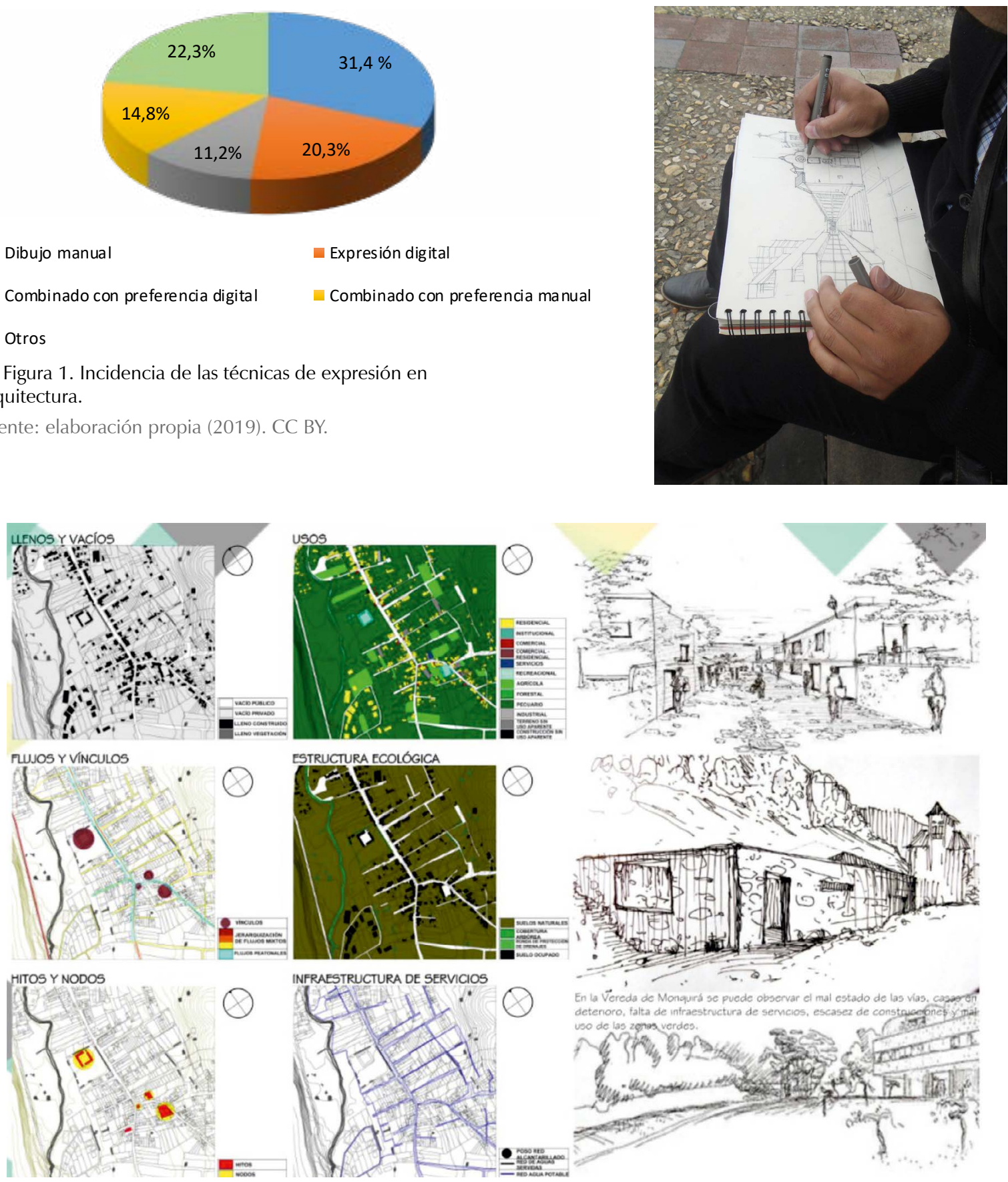

\section{Dibujo, pensamiento y creación}

Se revisan las incidencias que el dibujo aporta a la producción intelectual y al pensamiento en la labor del arquitecto, partiendo de su recursividad creativa.

Se abordó el tema desde un arquitecto preponderante como Le Corbusier, quien se refiere al dibujo como una oportunidad para observar y descubrir, donde el fenómeno inventivo puede suceder. Afirma que cuando se inventa o incluso se crea, todo el ser está involucrado en la acción; y así esta acción se convierte en el punto capital (Le Corbusier, 1960, p. 37). Adicionalmente, para Le Corbusier, "el dibujo permite determinado tipo de operaciones de percepción que — en el trabajo de una práctica creativa en las artes visuales - lo torna una herramienta fundamental del proyecto (tanto en la construcción de la obra como del propio autor)" (Rodrigues, 2011, p. 73).

A esta misma acción se refiere Anthi Kosma al afirmar que el dibujo contemporáneo no es la representación de un motivo externo, sino que parece más bien el desarrollo de un proceso totalmente inmerso en su propia acción. El dibujo aparece así más como el trazo fragmentado de un gesto que como resultado estático del mismo. (2016, p. 10)

\section{Así mismo, Francisco Granero indica que}

el dibujo, desde su creación intelectual en la mente, necesita del pensamiento y del acto de dibujar sobre el papel para la existencia de su comunicación, mediante un principio de abstracción y proceder a la estructuración de las formas hasta la ejecución de la imagen y de la figura (2017, p. 202). (figura 2)

Igualmente, Philip José Rodrigues (2011, p. 55) en su tesis doctoral acerca del dibujo, señala que este es una herramienta privilegiada en los procesos creativos, con una preponderancia en su eficacia de comunicación del trabajo, donde lo relevante es comunicar. Se diría, en consecuencia, que el acto de dibujar-comunicar-conocer se constituye para el arquitecto en parte esencial de los procesos creativos, a la que recurre como
\& Figura 2. Boceto a mano alzada.

Fuente: Facultad de

Arquitectura, Diseño y Urbanismo (2019). CC BY.
\& Figura 3. Proceso creativo para el análisis de la vereda Monquirá.

Fuente: Facultad de Arquitectura, Diseño y Urbanismo (2019). CC BY. 
alternativa de solución en situaciones problémicas de su competencia.

El acto creativo se asume también en el sentido de un proceso acumulativo; por ello, Manuel Bru cree que:

un dibujo acabado siempre es una huella o fragmento de algo más grande. Lo establece como la pista de una acción pasada y como parte de un todo, el cual es posible desarrollar mediante un proceso creativo que se nutre de un ir y venir constante. Un avanzar y retroceder fundamentado en el conocimiento del propio transcurso por el papel y la importancia de la repetición y la variación como mecanismos de progreso. (2016, p. 161)

Coincide en ello Javier Seguí de la Riva (2003), cuando afirma que "dibujar es un constante rectificar [...] tantear abierto y 'ciego' que sólo se puede desarrollar por sucesivas aproximaciones, estimuladas por lo que el propio dibujar presenta en cada momento reflexivo (perceptivo) como tanteo configurado" (p. 9).

Otro referente importante es Kahn, de quien Raúl Castellanos y Débora Domingo hablan en el sentido de que el propósito de sus dibujos consiste en persuadir a su audiencia mediante algo "más que un diagrama: un esbozo que sintetiza el pensamiento del arquitecto en los inicios del proceso creativo. Su esquematismo corresponde a un estadio inicial en el que la arquitectura aún no existe como imagen" (2013, p. 243). Puede afirmarse así que el pensamiento se patenta mediante el proceso creativo incluso antes de constituirse como representación implícita en una imagen arquitectónica (figura 3).

En relación con el vínculo entre dibujo y pensamiento, resulta conveniente partir desde los planteamientos filosóficos de Heidegger, quien afirma que "la mano en cada uno de sus trabajos lleva consigo el elemento del pensamiento, cada parte se soporta dentro de este elemento" (Heidegger, 2005, [1997], p. 78). En coincidencia, para Hernán Marchant (2016, p. 29), el proceso que se ha llamado "cadenas de construcción de pensamiento," se explica a través del uso del croquis de observación, el que permite grabar en la memoria la información sintética de los fenómenos observados. De igual manera, Javier Francisco Raposo, Mariasun Salgado y Belén Butragueño expresan que:

\section{Sabemos que la historia del dibujo es la historia del ser humano. El ser humano, en el momento que tiene conocimiento, pone una mano en la pared y echa tinta para que quede su mano en ella. $Y$ surge un dibujo que es el dibujo de la mano. (2018, p. 34)}

Complementariamente, Germán Hidalgo cree que "para entender el proceso proyectual no queda otra alternativa que seguir los pasos del proyectista, es decir: hacer de nuevo los dibujos. Qué mejor manera de demostrar, además, que el dibujo puede ser también una forma de generar conocimiento" (2016, p. 27). Se añade en consecuencia que la historia del ser humano y la evolución de su conocimiento se manifiestan a través de sus dibujos, aun valiéndose de herramientas tecnológicas para ello.

A través de la historia, el dibujo remite a los límites de la conciencia de la psicología, bien sean de quien los realiza o de quien los interpreta. De ahí que cualquier representación nos ofrezca mayor información sobre la mente de su autor que sobre la realidad que sustituye (Gombrich, 1994, p. 45).

$$
\begin{aligned}
& \text { Según Castellanos y Domingo (2013, p. 243) } \\
& \text { Hay dibujos de arquitectura cuya valía no depende } \\
& \text { solo de la destreza de su artífice. Dibujos ante los } \\
& \text { que se diría que no se siente la mano, pues care- } \\
& \text { cen de la vana pretensión del gesto caligráfico y } \\
& \text { persiguen un ideal de permanencia inasible para } \\
& \text { el artista individual. En ellos "el espíritu habla al } \\
& \text { espíritu". (Focillon, 2006, p 41) }
\end{aligned}
$$

En coincidencia Betty Edwards afirma que "el dibujo no solo pretende mostrar el objeto representado, sino que también muestra al que lo hace, convirtiéndose así, en una metáfora del artista" (1988, p. 27). Así, al proceso creativo a partir del dibujo se le puede considerar como un acto auto-gestado, una autopoiesis, o acto auto-organizador del arquitecto, con implicaciones que, además de generar conocimiento, trascienden su mero oficio a favor de su esencia humana.

\section{El conocimiento a mano, desde el ojo y la mente}

A propósito de la función de las manos y su equivalencia instrumental, Juhani Pallasmaa (2012, p. 54), afirma que "las herramientas no son inocentes, y que expanden nuestras facultades y guían nuestras acciones y pensamientos de maneras específicas". También establece una clara diferenciación entre lo realizado manualmente frente a lo efectuado a través de un instrumento digital, al sostener que es por completo erróneo pretender que dibujar un proyecto con lápiz es equivalente e intercambiable a realizarlo por computador, tomando en cuenta "la esencia de la unión de la mano, la herramienta y la mente" (Pallasmaa, 2012, p. 54).

Este mismo autor complementa su postura señalando que el computador "crea una distancia entre el autor y el objeto, mientras que el dibujo a mano, coloca al proyectista en un contacto háptico, con el objeto o el espacio" (Pallasmaa, 2010, p. 12). En concordancia con esto, Richard Sennett (2009, p. 115), profundiza en el papel que juega el dibujo a mano alzada en los procesos de ideación, resaltando la íntima relación que existe entre la mano como el órgano táctil, el ojo como órgano de la visión y el cerebro en su proceso de interpretación de los estímulos aportada por los sentidos, lo que denomina la "tríada de la mano inteligente"; es decir, la coordinación de la mano, el ojo y el cerebro.

$\mathrm{Al}$ respecto de la relación entre el cuerpo y la mente, Frank R. Wilson concluye que la mano es tan primordial como el cerebro en la vida de los humanos, y que por tal condición hace parte esencial de su aprendizaje (2002, p. 279). Coincide 
con ello Angelique Trachana, cuando afirma que "la manipulación de diversos materiales y herramientas para dibujar y construir modelos intensifican la percepción táctil y permiten completar el conocimiento a través de la visión." De similar manera lo hace Verónica Rossado (2017, p. 180) al sostener que

ningún software logrará representar las ideas con la habilidad artística y calidad del trazo del diseñador. La calidez del dibujo y la posibilidad de plasmar las ideas en cualquier momento, superficie o lugar, solo la puede realizar la mano humana. (figura 4)

Igualmente, Campo (2010, p. 23) cree que para manipular con precisión, aspectos fundamentales como la gravedad y el espacio, el arquitecto necesita tanto la cabeza como las manos, y que para dimensionar su pensamiento, este debe medir sus ideas pensando con las manos y construyendo con la cabeza. Coinciden en ello Jorge Llopis, Manuel Giménez y Hugo Barros (2013, p. 147), al afirmar que "el acto de dibujar, deviene en una actividad íntimamente ligada con el pensar". El gesto con la mano dota de forma a las percepciones. De esta manera, el dibujo más que descriptivo se constituye en un acto generativo. Mientras que, para José Ramón Machado (2016, p. 75), el boceto es el portador de un proceso mental de ida y vuelta, donde el arquitecto exterioriza sus ideas. El dibujo permanece siempre en transformación y constituye un gesto manual como expresión corporal de su pensamiento.

Al respecto, en sus reflexiones Alba Dorado sostiene que

las manos actúan como herramientas del intelecto, como instrumentos de conocimiento. Un conocimiento que se produce a la par que se representa, se dibuja, se pinta o se construyen maquetas. En definitiva, mientras se trabaja con las manos, se aprende a ver junto a los logros sucesivos de la representación, a partir de continuados reconocimientos que procuran una información que se obtiene al tiempo que se proyecta. (2013, p. 198)

De acuerdo con esto se encuentran Marta del Árbol y Rubén González (2011, p. 14), al afirmar que las manos son la herramienta básica, universal y directa para materializar lo pensado previamente. Estas cualidades las convierten en el mejor medio de transformación del espacio.

Podríamos entonces concluir que la mano es un recurso del pensamiento para elaborar ideas a partir del aprendizaje corporal y que la mediación por instrumentos de tecnología digital se trata solo de un recurso práctico de abreviación para la generación eficiente de conocimiento.

En relación con el aporte del organismo como instrumento corporal de aprendizaje encontramos que para Margarita Navarro:

de la mano nacen las más expresivas reacciones que tienen su origen en un mundo íntimo, orgánico. En el dibujo se transparenta todo el cuerpo (...). La mano está más o menos oculta en todas las formas construidas y reencontramos sus efectos como huellas remotas de ella, en todo lo formado. (2007, p. 20)

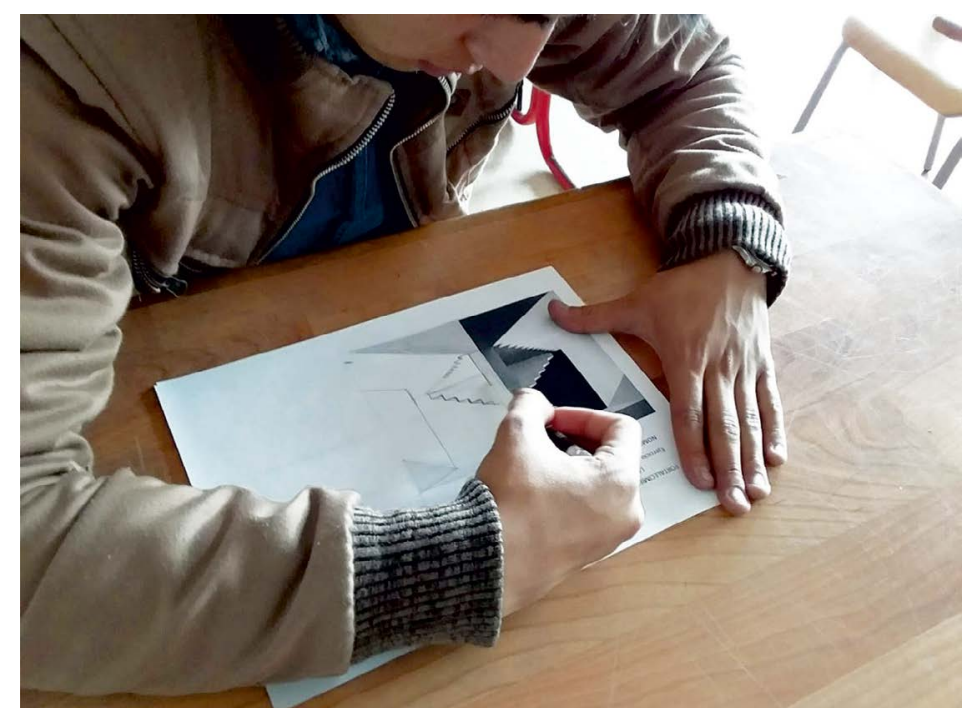

Coincide en ello Bolívar cuando señala que "en los dibujos, el registro de la mirada va más allá del punto de vista, comprende la organización y estructuración del campo óptico físico, del imaginario personal y muestran un envés orgániCo" (2018, p. 202).

$\mathrm{Si}$ adicionamos a lo anterior el conocimiento como experiencia física, encontramos que según Juan Gabriel Ocampo "el contacto real con el mundo elevado al plano inferencial prepara al individuo para la elaboración de ideas y argumentos frente a experiencias físicas determinadas" (2014, p. 10), aspecto vital en el caso de la arquitectura y su concepción, ya que, como afirma Vidaurre (1979, p. 41), en último término, el dibujo es siempre lugar, ocasión, traducción y expresión del denominado pensamiento arquitectónico, de donde deviene el conocimiento, ya no solo como un hecho individual sino como una experiencia común y recíproca de nuestra especie.

\section{El dibujo como lenguaje para el aprendizaje}

Mucho se ha dicho sobre el valor del dibujo en la arquitectura. Se afirma que "conocer en arquitectura es dibujar, condonándole al dibujo el valor de ser lenguaje y vía de expresión" (Flores, 2011, p. 9).

Para Dolores Martínez (2013, p. 49), el hombre siempre ha tenido la necesidad de la representación y esta se da en la relación entre "lo visto" y "lo real"; se complejiza aún más al manifestarse en un estado confuso entre "lo representado, la imagen" y "lo real". Mientras que Magali Delgado Yanes y Ernest Redondo Domínguez (2006, p. 93), sostienen que al concebir una obra arquitectónica se utiliza el dibujo como herramienta básica en el proceso de ideación y como medio de comunicación a terceros, simulando la realidad todavía no construida. De esta manera estaríamos hablando de que la finalidad de la representación no se trata tanto de obtener una imagen, ni si esta es algo real o aún por concretarse, sino, más bien, que lo que se busca con ella es comunicar las ideas y que estas se manifiestan a través de un lenguaje generativo, como lo es el dibujo para el caso de la arquitectura.
A Figura 4. Unión mano, herramienta y mente. Facultad de Arquitectura, Diseño y Urbanismo. (2019). CC BY. 
Un aspecto importante en relación con el papel del dibujo como ideación involucra sin duda al ser humano como aprendiente, nos referimos al estudiante. En tal sentido, señala Ricardo Martínez, que

la conversación en el diseño, ocurre por lo general, mediada por representaciones de carácter exploratorio, dibujos, modelos físicos y digitales, con los cuales el diseñador, y con mayor razón el estudiante, establece una ecología. Hablamos de un sistema en el cual hay un organismo y una porción del ambiente que se determinan recíprocamente: el diseñador, por un lado; y los dibujos y/o modelos, por otro. (2014, p. 14)

\section{Al respecto, Carlos Niño afirma}

lo importante no es que el arquitecto [o estudiante], dibuje bonito o feo, sino que dibuje bien, es decir que plantee una espacialidad y su tectónica, pensando en los espacios que imagina construidos y no en los grafismos que traza. (2006, p. 50)

Si se pretende incrementar la capacidad creativa de los estudiantes, así como su curiosidad y actitud exploratoria, se debe hablar del dibujo como estrategia de emprendimiento, tal como indica Juan Puebla Pons cuando se refiere a la evolución de la representación, donde

\begin{abstract}
lejos de constituir un simple instrumento que muestre la apariencia de la arquitectura, pasaba a formar parte de su propia esencia como elemento generador, inseparable de su proceso de producción. Se pretendía elevar el nivel arquitectónico al extender y potenciar el carácter indagatorio profundo del dibujo en el proyecto. (2006, p. 133)
\end{abstract}

Por su parte, Álvaro Siza (2003, p. 7), asocia el aprendizaje a la aprehensión cuando sostiene que el dibujo es una forma de aproximación al proyecto, donde se ejecuta una "aprehensión que permite ampliar la mirada y la sensibilidad sobre el lugar" (Bolívar, 2018, p. 207). En resonancia con ello, James Faure Walker involucra muy sugestivamente el dibujo como estrategia de auto-aprendizaje cuando asevera que

hoy en día nos gusta pensar que trabajamos en un 'campo expandido' del dibujar, aplicando la fenomenología, empujando hacia los límites, colonizando actividades como el map-making (mapeado) o la escritura diaria. Los aspectos más precisos de la técnica, sea el lápiz, el bolígrafo, el pincel, el software, o incluso la perspectiva, son menos importantes. Los estudiantes son libres de aprender sus propias 'destrezas' a su propio tiempo. (2008, p. 88)

\section{Entre el dibujo a mano alzada y la digitalización}

Frente a la constante polémica entre lo que resulta más conveniente para la proyectación arquitectónica en materia de representación manual o digital, se han revisado diversas fuentes, entre las cuales cabe citar a Virginia Arnet, quien piensa que

1 Today we like to think we work in 'an expanded field' of drawing, applying phenomenology, pushing at the limits, colonising activities like map-making and diary writing The finer points of technique, whether pencil, pen, brush drawing software, or even perspective, are less important. The students are left to learn 'skills' in their own time (traducción propia). la discusión al respecto del manejo de software y máquinas contemporáneas en la creación de proyectación arquitectónica es punta de lanza en el debate de representación gráfica del siglo XXI, ya que si bien presenta aspectos positivos (reduce los tiempos de representación de manera abismal con las herramientas tradicionales), pierde la componente subjetiva apareciendo un mundo de imágenes dominante sobre la imaginación y los aspectos intangibles de una obra arquitectónica. (2016, p. 15)

En este mismo sentido, Rafael Moneo (citado por Massad, 2017, párr. 5), sostiene que "a pesar de creer que la cultura digital llevará inevitablemente a nuevos modos de representación y de transmisión de la información acerca de cómo construir, la arquitectura se piensa siempre desde el dibujo". Concuerdan con él Moneo Simone Tanoue, Paulo Castral y Joubert Lancha (2011), cuando indican que el boceto a mano alzada es una herramienta primordial que permite la interacción "entre el autor y el proyecto; la conexión cuerpo, mente y expresión en los primeros pasos de la concepción, a los que los medios digitales y sus recursos pueden ayudar" (Machado, 2016, p. 79), pero es importante "preservar la sensibilidad y la habilidad artística del estudiante, evitando el uso excesivo de herramientas digitales en el proceso de aprendizaje y el ejercicio de la arquitectura" (Rossado, 2017, p. 181) (figura 5)

Otros autores, como Juan Otxotorena, creen, en cambio, que
la tecnología informática ha abierto el panorama en una medida definitiva que obliga a resituar nuestra relación personal con el lápiz. Ella ha de ser replanteada a la luz de una profunda revisión de la naturaleza de los procesos de diseño, ligada a la identificación cabal de sus resortes y su genuina variabilidad. (2007, p. 72)

En ese mismo sentido, Antonio Sahady, piensa que

el buen dibujo a mano alzada ha dejado de constituir un arma de expresión natural de los estudiantes. La evolución de los medios digitales y de los programas de Autocad resta valor al desarrollo de aquellas destrezas que, en el pasado, fueron patrimonio insustituible de quienes ejercían el oficio de la arquitectura. (2016, p. 36)

A favor del uso de herramientas digitales encontramos a autores como Underlea Bruscato (2006, p. 3), quien plantea que la introducción del computador en el proceso de expresión proyectual de una obra arquitectónica viene siendo una herramienta necesaria para definir un proyecto arquitectónico. Bernal (2013, p. 1), concuerda con esto, al afirmar que la expresión digital del proyecto arquitectónico ha dado la oportunidad para concebir las geometrías de la arquitectura contemporánea. Las imágenes digitales destacan los valores del edificio presentando imágenes perfectas con cualidades estéticas. De la misma forma lo aprecia Antoine Picon (2006, p. 11), cuando asevera que así la arquitectura sufrió una gran transformación, y evolucionó como nunca antes, proporcionando nuevas herramientas de representación arquitectónica. "Se cuenta 
arquitectura, la matemática y la informática se han dado la mano y la tecnología se ha convertido en un atractivo desafío que permite concebir, conceptualizar, generar y desarrollar, analizar, evaluar, sintetizar, compartir, presentar y discutir ideas de diseño que provocan una nueva organización de formas y espacios arquitectónicos. (2014, p. 5)

lo anterior encaja dentro de lo que se puede apreciar en la figura 6.

Mientras otros autores como Gonzálo Muñoz y Roberto Goycolea le apuestan a una situación indeterminada al señalar que

la producción, manipulación y difusión de la fotografía digital es cada vez más sencilla, instantánea y económica. A lo que cabe sumar unos programas informáticos que ofrecen instrumentos inéditos para re-dimensionar, re-colorear, combinar las fotografías, así como reconvertirlas en dibujos de cualquier técnica o producir dibujos de calidad fotográfica. Como espectadores, la invención y generalización de la fotografía digital difundida por Internet nos enfrenta a un torbellino interminable de imágenes, cuyo verdadero alcance profesional y docente no termina de aclararse. (2016, p. 20)

En cuanto a la relevancia de las habilidades digitales por ser implementadas en las facultades de diseño arquitectónico, existen autores como Machado, quien afirma que "con la aparición de la tecnología surge la necesidad de dominar la habilidad, conocida como la expresión digital aplicada en el campo de la arquitectura" (2016) en función de los requerimientos del mundo actual; por tal razón, en el plan de estudios de la carrera de arquitectura se incluyen estos nuevos contenidos en el área de representación gráfica. Mientras que para Rossado, al usar estas herramientas digitales,

el alumno puede ser capaz de desarrollar nuevas competencias relacionadas con el diseño proyectual como apoyo técnico y constructivo (...) el empleo excesivo de estas tecnologías en los estudiantes interfiere en el logro de otras competencias esenciales para el arquitecto como la habilidad de dibujar manualmente, fundamental como parte del proceso de diseño y expresión de ideas. (2017, p. 178)

Otros autores, como Enrique Echeburúa, Francisco Javier Labrador y Elisardo Becoña, se preocupan por las incidencias que esta situación conlleva, para ellos "las nuevas tecnologías de la información (TIC) han revolucionado el estilo de vida de los adultos, pero sin duda el cambio más espectacular se ha producido en los menores, que ya han nacido con estas nuevas tecnologías." (2009, p 23). Estas herramientas generan en los jóvenes problemas como las adiciones, a los juegos, a la tecnología y, en el peor de los casos, a las drogas. Por su lado Edgar Erazo y Pável Sánchez, reconocen

los cambios producidos por la mediación digital en los procedimientos proyectuales y en las nociones de forma. Hoy se encuentra en estudio la codificación de esos cambios, investigando la conformación y superposición de códigos disciplinares y sociales en circunstancias de fluidez, perdida de certezas y transformación de procedimientos y estéticas tradicionales, en un contexto en el que lo global interviene en lo propio. (2013, p. 776)
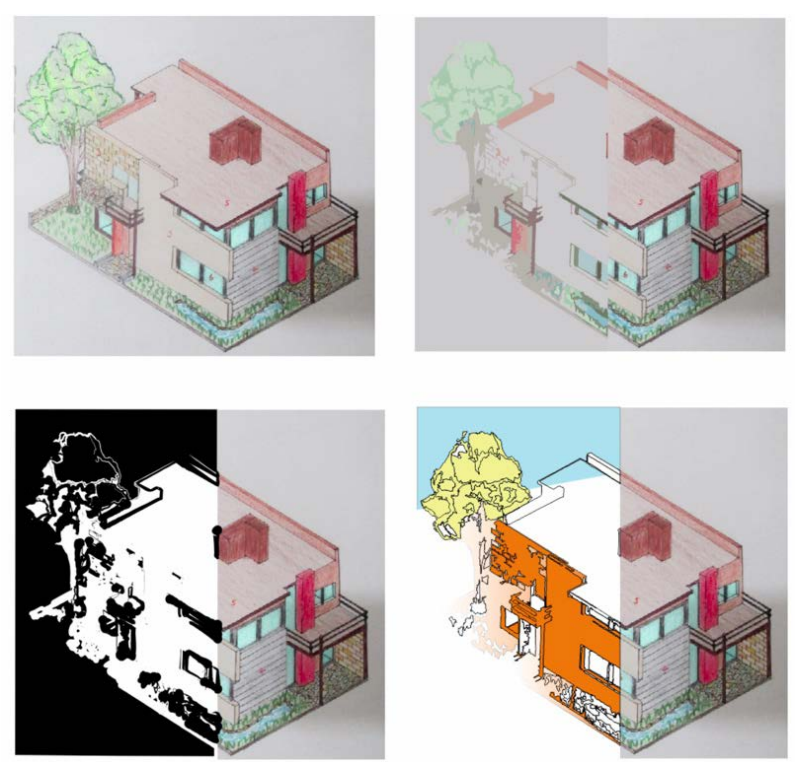

Figura 5. Combinación de dibujo manual y digital. Fuente: Facultad de Arquitectura, Diseño y Urbanismo. (2019). CC BY.

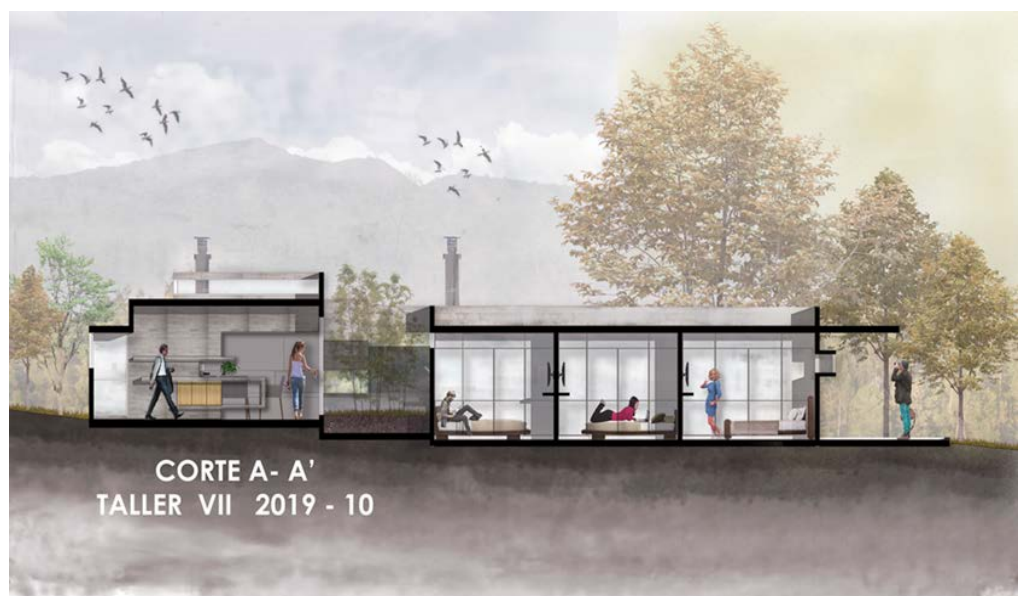

En coincidencia, Nicholas Carr (citado por Clemente, 2011, párr. 1) refiere que el uso de Internet está cambiando nuestros hábitos cerebrales, acostumbrándonos a un consumo fragmentario, caracterizado por ir saltando de párrafo en párrafo evitando los textos largos y completos. En este mismo sentido Rossado advierte que en

(A) Figura 6. Fotomontaje combinación de dibujo manual y digital. Fuente: Facultad de Arquitectura, Diseño y Urbanismo, (2019). CC BY.

\begin{abstract}
el entorno educativo en el aspecto digital, será necesario que el alumno adquiera diversas actitudes de responsabilidad y ética, ante la facilidad de acceso a la información. La gran cantidad de proyectos arquitectónicos publicados en la web, pueden motivar el plagio y atentar contra la originalidad y la creatividad (2017, p. 180)
\end{abstract}

Varios autores coinciden en que las nuevas tecnologías hacen del llamado ciberplagio la más frecuente práctica entre los estudiantes universitarios (Domínguez-Aroca, 2012).

Por último, se hace necesario en las aulas de arquitectura relacionar los dos medios de expresión estudiados, sin dejar la técnica manual para volverse experto en la otra técnica, o viceversa. Se debe buscar el equilibrio en las técnicas, combinarlas y así obtener los mejores resultados de cada una de ellas. Se propone poner en práctica ejercicios que incluyan las dos técnicas, analizando el tipo de herramientas que se pude combinar mejor para el desarrollo del ejercicio (Erazo \& Sánchez, 2013, p. 777).

Sin duda, estos últimos autores de alguna maneraherramientas que se pude combinar mejor para el desarrollo del ejercicio (Erazo \& Sánchez, 2013, p. 777). 
Sin duda, estos últimos autores de alguna manera rescatan las bondades y las ventajas inherentes a cada una de las formas de representación arquitectónica. Tanto los recursos manuales como las herramientas digitales hacen grandes aportes en el ejercicio de la arquitectura, y por tanto, lo ideal es combinar y alternar las dos opciones. Reconocidos estudios y arquitectos aplican indiscriminadamente las dos técnicas con excelentes resultados, confirmando expresamente esta recomendación.

En tal sentido, este trabajo contribuye particularmente con los entornos académicos locales y regionales aportando para las estrategias de enseñanza-aprendizaje, considerando particularmente la ambivalencia que se detecta desde la introducción de la digitalización, y la consecuente relegación a un segundo término de la representación manual en la proyectación arquitectónica.

\section{Conclusiones}

Si bien los autores revisados se ubican mayoritariamente en una delimitación espacio-temporal circunscrita a Latinoamérica, todos tienden a expresar sus posiciones y sus opiniones en términos genéricos y/o universales, en razón de que en la realidad actual predomina una mirada global sin mayores referencias locales. En este sentido, valdría la pena para una segunda parte de la investigación, ampliar la consulta desde referentes que trasciendan lo regional. La única excepción de localidad, tristemente señala el rezago tecnológico de nuestra región, razón por la cual ciertas herramientas y programas digitales aun no son de extensa aplicación en nuestro medio, incluyendo los medios digitales de expresión y representación proyectual para la arquitectura.

En relación con el factor de interés de esta investigación, el cual se refiere al vínculo entre el dibujo con el aprendizaje, la creatividad y el pensamiento, se concluye que sin distinguir la técnica empleada para dibujar, sea manual o digital, siempre va implícito un factor emocional y relacional que asocia de manera simultánea el pensamiento con el aprendizaje, mientras se generan ideas creativas asociadas al proyecto arquitectónico. Por tal razón se recomienda tener presente dicho aspecto al momento de formular estrategias pedagógicas en las instituciones y los programas de diseño y arquitectura, que desborden la tradicional concepción de que el dibujo juega un papel meramente representacional cuya función se limita a contener detalles técnicos, funcionales y estéticos.

Igualmente, cuando se habla de competencias de formación, debe tenerse presente la multidisciplinariedad de estas, en donde lo ideacional, proyectual, representacional y constructivo van integrados simultáneamente. Así, con la incentivación de la práctica del dibujo se están potenciando habilidades como operaciones de percepción y los principios de abstracción, donde, a partir de procesos de reestructuración de la forma se conciben imágenes y figuras.
Adicionalmente, y conexo a la capacidad de comunicación encontramos que al incorporar la tecnología en los procedimientos de ideación y representación arquitectónica, se está aumentando la posibilidad de manipular y explorar grandes volúmenes de información, lo que manejado de manera correcta, redundará en un incremento de la creatividad, en donde se corrobora que el dibujo es también una forma de generación de conocimiento.

En cuanto al segundo tema de interés de esta investigación, que se refiere a la función que desempeña la relación entre mano, ojo y mente frente a la generación de ideas mediante el acto de dibujar, se puede señalar de igual manera la importancia de no perder de vista, a la hora de implementar estrategias pedagógicas en la enseñanza de la arquitectura, que la práctica del dibujo incluye cualidades sensitivas, táctiles y gestuales, además de las visuales. En este sentido recomendamos tener presente que la mano es tan esencial como el cerebro para los procesos de aprendizaje, y que sus acciones gestuales a través del dibujo implican procedimientos de generación y transformación de formas, donde el pensamiento se manifiesta a través de la expresión corporal.

En relación con nuestro último tema de interés, que se refiere a la incidencia en el entorno proyectual que implica el dibujo, según si se realiza de manera manual, digital o combinada, se concluye que, más que señalar las ventajas o las desventajas que cada uno ofrece, se encontraron aspectos novedosos que enriquecen el proceso de aprendizaje de la arquitectura. Allí se acota que, si bien es inevitable que la cultura digital genere nuevas formas de transmisión y representación para la ideación en diseño, la arquitectura siempre será pensada desde el dibujo. Cabe destacar el hecho de que la tecnología permite responder a las exigencias de los paradigmas emergentes contemporáneos en cuanto a la organización de formas y espacios. Ello implica la necesidad de desarrollar nuevas competencias a partir del dominio de la expresión digital, que apoyen los desafíos técnicos y constructivos asociados. La arquitectura y la manera como se la enseña deben adaptarse a las concepciones emergentes sociales, su superposición disciplinar, fluidez, incertidumbre, relevo de códigos y transformación de las estéticas tradicionales.

El dibujo es un recurso privilegiado para los procesos creativos donde se patenta la acción inventiva y de innovación, que se constituye en la acción central y la esencia para la producción en la arquitectura. Es fundamental para el diseñador comunicar su pensamiento, producto de un proceso perceptivo y reflexivo manifiesto mediante sus dibujos.

Fomentar la ideación para el proyecto arquitectónico a partir del dibujo, bien sea desde su fundamentación más sencilla (dibujo a mano) o desde sus aplicaciones más sofisticadas (dibujo digital), fortalecerá notablemente los resultados y la resolución asertiva de los problemas por resolver en el ejercicio del diseño y la construcción tanto a escala profesional como, con mayor razón, en el nivel de formación de los arquitectos. 


\section{Referencias}

Alba Dorado, M. (2013). Manos que piensan. Reflexiones acerca del proceso creativo del proyecto de arquitectura. EGA Expresión Gráfica Arquitectónica, 18(22), 196-203. https://doi.org/10.4995/ega.2013.1694

Arnet, V. (2016). Las manos del arquitecto: aproximaciones al pensamiento físico en la arquitectura. Revista Arteoficio, "El dibujo" (12), 11-16. Recuperado de:

http://www.revistas.usach.cl/ojs/index.php/ arteoficio/article/view/2879/2607

Bernal A. (2013). Dibujo de imágenes o arquitectura dibujada. Revista disegnarecon (12), 1-10. Doi: https://doi.org/10.6092/issn.1828-5961/3851

Bolívar Montesa, C. (2018). La adjetivación de la mirada a través del dibujo. EGA Expresión Gráfica Arquitectónica, 23(33), 202-214. doi: https://doi.org/10.4995/ega.2018.10394

Bru Serrano, M. (2016). El dibujo como huella y fragmento. Un camino de ida y vuelta. Revista de Artes Plásticas, Estética, Diseño e Imagen, (13), 161-181. Recuperado de: https://www.ull.es/revistas/index.php/artes/ article/view/359

Bruscato, U. (2006). De lo digital en Arquitectura (Tesis Doctoral). Escuela Técnica Superior de Arquitectura de Barcelona (ETSABUPC), España. Recuperado de:: http://hdl.handle.net/10803/6560

Burneo Valdivieso, X. E. (2014). Arquitectura del siglo XXI: digital, inteligente y creativa. Revista Perspectivas. 1(3).

Recuperado de: http://dspace.utpl.edu.ec/ handle/123456789/15433

Campo, A. (2010). Pensar con las manos. Buenos Aires: Nobuko.

Castellanos Gómez, R., \& Domingo Calabuig, D. (2013). El valor y el propósito de un dibujo de Louis I. Kahn. EGA Expresión Gráfica Arquitectónica, 18(22), 242-251. doi: https://doi.org/10.4995/ega.2013.1253

Clemente, E. (2011, abril 02). Nicholas Carr: Internet erosiona el pensamiento profundo. La voz de Galícia [Periódico en línea].

Recuperado de:: https://www.lavozdegalicia. es/noticia/tecnologia/2011/04/02/nicholascarr-internet-erosiona-pensamientoprofundo/0003_201104SC2P14991.htm

Del Árbol, M. y González, R. (2011). Transformando espacio y creando identidad. Revista "Hipo-Tesis", Hipo I (9).

Recuperado de:: http://www.hipo-tesis. eu/numero_hipo_i.html

Delgado Yanes, M. y Redondo Domínguez, E. (2006). Dibujo a mano alzada para arquitectos. Barcelona: Parramón.

Domínguez-Aroca, M. I., (2012). Lucha contra el plagio desde las bibliotecas universitarias. El profesional de la información 21(5), 498503.

Doi: http://dx.doi.org/10.3145/epi.2012.sep.08

Echeburúa, E., Labrador, F., y Becoña, E. (2009). Adicción a las nuevas Tecnologías en adolescentes y jóvenes. Madrid: Pirámide.

Edwards, B. (1988). Aprender a dibujar. Madrid: Lavel.

Erazo, E. \& Sánchez, P. (2013). Incidencia de medios de expresión digital en formación de arquitectos y arquitectas. Revista Latinoamericana de Ciencias Sociales, Niñez y Juventud, 11 (2), pp. 769-781. Recuperado de:: http://biblioteca.clacso.edu.ar/Colombia/ alianza-cinde-umz/20140715062109/art. EdgarDiegoErazo.pdf

Faure Walker, J. (2008). Pride, prejudice and the pencil. En: Writing on drawing, essays on drawing practice and research.(Ed. Steve Garner) UK: NSEAD.
Flores Soto, J. A. (abril, 2011). Los dibujos del arquitecto. Revista "Hipo-Tesis", "Hipo 1" (9) p. 9. Recuperado de:: http://www.hipo-tesis.eu/fscommand/I/09. pdf

Focillon, H. (2006). Elogio de la mano. México: Universidad Nacional Autónoma.

Gombrich, E. (1994). Imágenes Simbólicas. Madrid: Alianza.

Granero Martín, F. (2017). Como pez en el agua. Reflexiones sobre dibujo y pensamiento. EGA Expresión Gráfica Arquitectónica, 22(30), 198-205. doi: https://doi.org/10.4995/ega.2017.7833

Heidegger, M. (2005). ¿Qué significa pensar? Madrid: Trotta.

Hidalgo, G. (2016). Dibujo y creatividad: relectura de un artículo de Robin Evans. Revista Arteoficio, "El dibujo" (12), 23-28. Recuperado de:

http://www.revistas.usach.cl/ojs/index.php/ arteoficio/article/view/2881/2609

Kosma, A. (2016). Del dibujo al dibujar. Cambios generacionales, metamorfosis y aperturas de un término. Revista Arteoficio, "El dibujo". (12), 5-10. Recuperado de: http://www.revistas.usach.cl/ojs/index.php/ arteoficio/article/view/2878/2606

Le Corbusier. (1960). Le Corbusier, I'atelier de la recherche patiente. Vincent Freal Cie, Paris.

Llopis Verdú, Jorge, Giménez Ribera, Manuel, \& Barros da Rocha e Costa, Hugo A. (2013). El boceto arquitectónico en la era digital. Arquiteturarevista, 9(2),143-152.Recuperado de:: http://revistas.unisinos.br/index. php/arquitetura/article/viewFile/ arq.2013.92.07/3890

Machado González, J. (2016). El boceto arquitectónico, entre el trazo a mano y el clic digital. DeSigno: diseño integral, donde convergen arte, ciencia y tecnología, 0(2), 72-83. Recuperado de::

http://erevistas.saber.ula.ve/index.php/ designo/article/view/8057/8009

Marchant, H. (2016). El dibujo en la construcción del pensamiento de Le Corbusier. Revista Arteoficio, "El dibujo" (12), 29-34. Recuperado de: http://www.revistas.usach.cl/ojs/ index.php/arteoficio/article/view/2882/2610

Martínez, D. (2013). Un tacto claro en el umbral oscuro del sentido. Revista "Hipo-Tesis", "Hipo 1" (Sobre las manos/ About Hands), 48-56. Recuperado de:

http://www.hipo-tesis.eu/numero hipo 1.html

Martínez, R. (2014). Diseñar - conversar conocer, "La enseñanza de la arquitectura". (10), 12-15.

Recuperado de: http://www.revistas.usach.cl/ ojs/index.php/arteoficio/article/view/1526/1413

Massad, F. (2017, abril 02). Rafael Moneo: La arquitectura se piensa siempre desde el dibujo. ABC Cultural [periódico en línea]. Recuperado de:: https://www.abc.es/cultura/cultural/abcirafael-moneo-arquitectura-piensa-siempredesde-dibujo-201704020050_noticia.html

Muñoz, G., y Goycolea, R. (2016). Interacciones arquitectónicas recurrentes en la simbiosis dibujo-fotografía. Revista Arteoficio, "El dibujo" (12), 17-21.

Recuperado de:: http://www.revistas. usach.cl/ojs/index.php/arteoficio/article/ view $/ 2880 / 2608$

Navarro, J. (2007). Una caja de resonancia. Girona: Collegi d'Arquitectes de Catalunya, Demarcació de Girona.

Niño, C. (2006). Notas de Clase. Bogotá, D. C.: Unibiblos.

Ocampo Hurtado, J. (2014). Evaluación, didáctica y enseñanza de la arquitectura: una experiencia hermenéutica. Praxis \& Saber, 5(9), 31 - 52 https://doi.org/10.19053/22160159.2992

Otxotorena, J. (2007). Dibujo y proyecto en el panorama de la arquitectura contemporánea: impacto e influjo de los nuevos procedimientos gráficos. EGA Expresión Gráfica Arquitectónica, 12(12), 60-73. doi: https://doi.org/10.4995/ega.2007.1029

Pallasmaa, J. (2010). Los ojos de la piel. Barcelona: Gustavo Gili.

Pallasmaa, J. (2012). La mano que piensa. BarceIona: Gustavo Gili.

Picón, A. (2006). Arquitectura y virtualidad: Hacia una nueva condición material. $A R Q$ (Santiago) (63), 10-15.

https://dx.doi.org/10.4067/S071769962006000200002

Puebla Pons, J. (2006). Sobre la innovación expresiva del proyecto contemporáneo. EGA Expresión Gráfica Arquitectónica, 11(11), 132-141.

https://doi.org/10.4995/ega.2006.10322

Raposo Grau, J., Salgado de la Rosa, M., \& Butragueño Díaz-Guerra, B. (2018). conversando con... Emilio Tuñón (parte 2): Dibujar para entender II. La mano que piensa, procesa, construye. EGA Expresión Gráfica Arquitectónica, 23(33), 14-39. https://doi.org/10.4995/ega.2018.10391

Rodrigues, P. (2011). El dibujo como dispositivo pedagógico (tesis doctoral). España: Universidad Politécnica de Valencia.

Recuperado de:: https://riunet.upv.es/bitstream/ handle/10251/15176/tesisUPV3638. pdf? sequence $=1$

Rossado Espinoza, V. (2017). La importancia del dibujo en la formación del arquitecto: Equilibrio entre el diseño digital y el analógico. XXI Congreso de la Sociedad Ibero-americana de Gráfica Digital, Blucher Design Proceedings. 3 (12). pp. 178-184. https://doi.org/10.5151/sigradi2017-028

Sahady, A. (2016). De la palabra al trazo. Revista Arteoficio, "El dibujo". (12), 35-39.

Recuperado de:: http://www.revistas.usach. cl/ojs/index.php/arteoficio/article/view/2883

Seguí de la Riva, J. (2003). Dibujar Proyectar I, II-LVII. Madrid: Instituto Juan de Herrera de la Escuela de Arquitectura de Madrid.

Sennett, R. (2009). El artesano. Barcelona: Anagrama.

Siza, Á. (2003). Imaginar la evidencia. Madrid: Abada.

Tanoue, S., Castral, P., y Lancha, J. (2011). Freehand drawing and digital representation: a discussion in the architectonic projective process. IV Jornadas Internacionales sobre Investigación en Arquitectura y Urbanismo, Valencia, España. Recuperado de::

http://www.iau.usp.br/pesquisa/grupos/ nelac/wp-content/uploads/2015/01/2011 Valencia_Freehanding-drawing-and-digitalrepresentation.pdf

Trachana, A. (2012). Manual o digital. Fundamentos antropológicos del dibujar y construir modelos arquitectónicos. EGA Expresión Gráfica Arquitectónica, 17(19), 288-297. https://doi.org/10.4995/ega.2012.1381

Vidaurre, J. Et otros (1979). La expresión gráfica arquitectónica de la Plaza Mayor de Madrid a través del lenguaje gráfico. Madrid: Colegio de arquitectos de Madrid. Colección Cátedras $\mathrm{n}^{\circ} 1$.

Wilson, F. (2002). La mano. Barcelona: Tusquets. 


\section{Vol.}
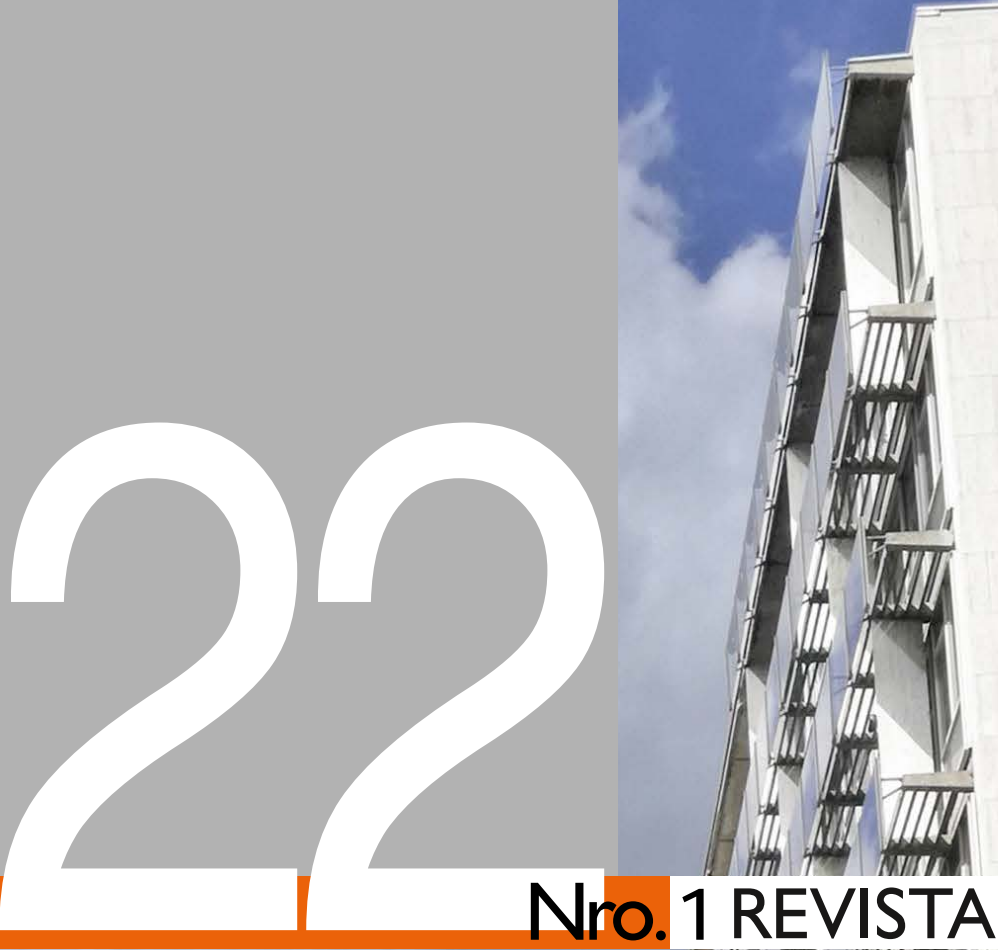

ISSN: 1657-0308 (Impresa)

Nro. 1 REVISTA DE ARQUITECTURA

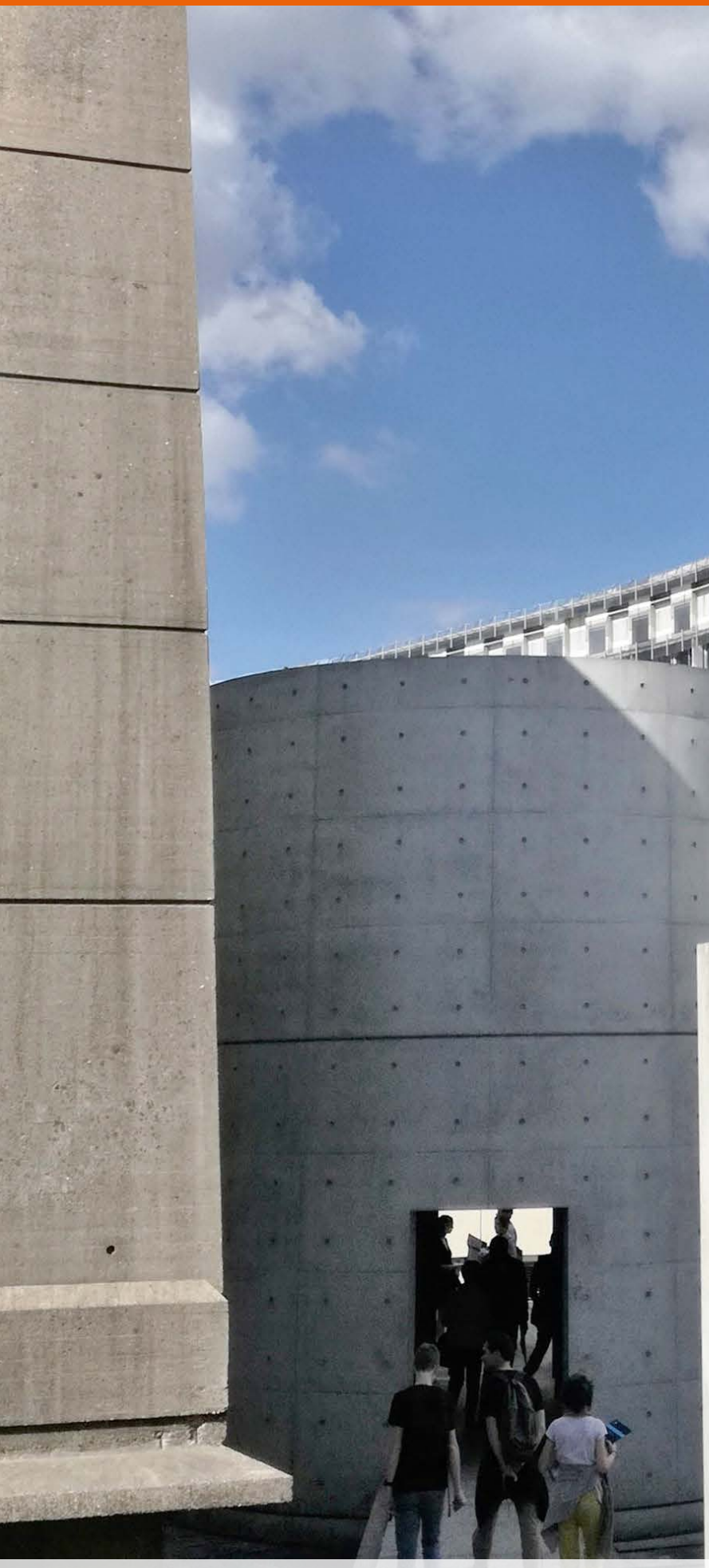

$\overline{9}$
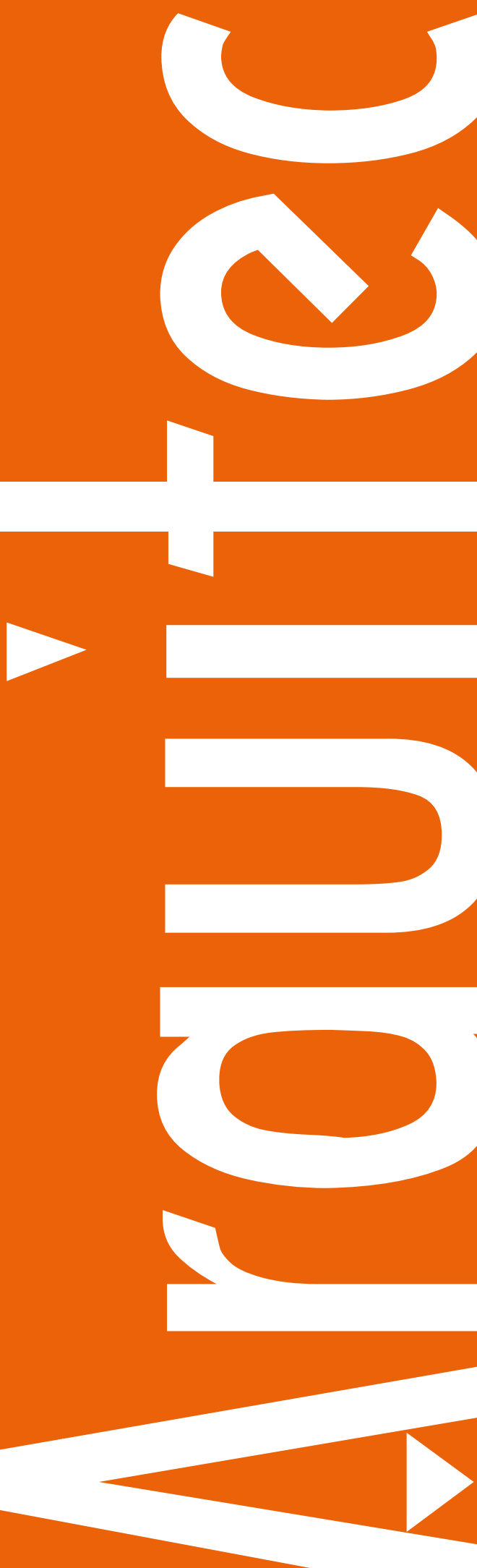


\section{Enfoque y alcance}

La Revista de Arquitectura (Bogotá) ( (ISSN 1657-0308 Impresa y E-ISSN 2357-626X en línea) es una publicación científica seriada de acceso abierto, arbitrada mediante revisión por pares (doble ciego) e indexada, en donde se publican resultados de investigación originales e inéditos.

Está dirigida a la comunidad académica y profesional de las áreas afines a la disciplina. Es editada por la Facultad de Diseño y el Centro de Investigaciones (CIFAR) de la Universidad Católica de Colombia en Bogotá (Colombia).

La principal área científica a la que se adscribe la Revisto de Arquitectura (Bogotá) según la OCDE es:

Gran área: 6. Humanidades

Área: 6.D. Arte

Disciplina: 6D07. Arquitectura y Urbanismo

También se publican artículos de las disciplinas como 2A02, Ingeniería arquitectónica; 5C03, Estudios urbanos (planificación y desarrollo); 6D07, Diseño.

Los objetivos de la Revista de Arquitectura (Bogotá) son:

- Promover la divulgación y difusión del conocimiento generado a nivel local, nacional e internacional

- Conformar un espacio para la construcción de comunidades académicas y la discusión en torno a las secciones definidas.

- Fomentar la diversidad institucional y geográfica de los autores que participan en la publicación.

- Potenciar la discusión de experiencias e intercambios científicos entre investigadores y profesionales.

- Contribuir a la visión integral de la arquitectura, por medio de la concurrencia y articulación de las secciones mediante la publicación de artículos de calidad.

- Publicar artículos originales e inéditos que han pasado por revisión de pares, para asegurar que se cumplen las normas éticas, de calidad, validez científica, editorial e investigativa.

- Fomentar la divulgación de las investigaciones y actividades desarrolladas en la Universidad Católica de Colombia.
Palabras clave de la Revista de Arquitectura (Bogotá): arquitectura, diseño, educación arquitectónica, proyecto y construcción, urbanismo.

Idiomas de publicación: español, inglés, portugués y francés. Título abreviado: Rev. Arquit.

\section{Titulo corto: RevArq}

\section{Políticas de sección}

La revista se estructura en tres secciones correspondientes a las líneas de investigación activas y aprobadas por la institución, y dos complementarias, que presentan dinámicas propias de la Facultad de Diseño y las publicaciones relacionadas con la disciplina.

Cultura y espacio urbano. En esta sección se publican los artículos que se refieren a fenómenos sociales en relación con el espacio urbano, atendiendo aspectos de la historia, el patrimonio cultural y físico, y la estructura formal de las ciudades y el territorio.

Proyecto arquitectónico y urbano. En esta sección se presentan artículos sobre el concepto de proyecto, entendido como elemento que define y orienta las condiciones proyectuales que devienen en los hechos arquitectónicos o urbanos, y la forma como estos se convierten en un proceso de investigación y nuevo de conocimiento. También se presentan proyectos que sean resultados de investigación, los cuales se validan por medio de la ejecución y transformación en obra construida del proceso investigativo. También se contempla la publicación de investigaciones relacionadas con la pedagogía y didáctica de la arquitectura, el urbanismo y el diseño.

Tecnología, medioambiente y sostenibilidad. En esta sección se presentan artículos acerca de sistemas estructurales, materiales y procesos constructivos, medioambiente y gestión, relacionados con los entornos social-cultural, ecológico y económico.

Desde la Facultad. En esta sección se publican artículos generados en la Facultad de Diseño, relacionados con las actividades de docencia, extensión, formación en investigación o internacionalización, las cuales son reflejo de la dinámica y de las actividades realizadas por docentes, estudiantes y egresados; esta sección no puede superar el $20 \%$ del contenido.

Textos. En esta sección se publican reseñas, traducciones y memorias de eventos relacionados con las publicaciones en Arquitectura y Urbanismo.
A Frecuencia de publicación

Desde 1999 y hasta el 2015, la Revista de Arquitectura (Bogotá) publicó un volumen al año, a partir del 2016 se publicarán dos números por año en periodo anticipado, enero-junio y julio-diciembre, pero también maneja la publicación anticipada en línea de los artículos aceptados (versión Post-print del autor).

La Revista de Arquitectura (Bogotá) se divulga mediante versiones digitales (PDF, HTML, EPUB, XML) e impresascon un tiraje de 700 ejemplares, los tiempos de producción de estas versiones dependerán de los cronogramas establecidos por la editorial.

Los tiempos de recepción-revisión-aceptación pueden tardar entre seis y doce meses dependiendo del flujo editorial de cada sección y del proceso de revisión y edición adelantado.

Con el usuario y contraseña asignados, los autores pueden ingresar a la plataforma de gestión editorial y verificar el estado de revisión, edición o publicación del artículo.

\section{A Canje}

La Revista de Arquitectura (Bogotá) está interesada en establecer canje con publicaciones académicas, profesionales o científicas del área de Arquitectura y Urbanismo, como medio de reconocimiento y discusión de la producción científica en el campo de acción de la publicación.

\section{Mecanismo}

Para establecer canje por favor descargar, diligenciar y enviar el formato: RevArq FP20 Canjes
Universidad Católica de Colombia (2020, enero-junio). Revista de Arquitectura (Bogotá), 22(I) I-188. Doi: 10.14718

ISSN: 1657-0308 E-ISSN: 2357-626X

Especificaciones:

Formato: $34 \times 24 \mathrm{~cm}$

Papel: Mate $115 \mathrm{~g}$

Tintas: Negro y policromía
A Contacto

Dirección postal:

Avenida Caracas No. 46-72.

Universidad Católica de Colombia

Bogotá D.C.(Colombia)

Código postal: 111311

Facultad de Diseño Centro de Investigaciones (CIFAR). Sede El Claustro. Bloque " $\mathrm{L}$ ", 4 piso Diag. 46A No. $15 \mathrm{~b}-10$ Editor, Arq. César Eligio-Triana

Teléfonos:

+57 (1) $3277300-3277333$

Ext. 3109; 3112 o 5146

Fax: +57 (1) 2858895
Correo electrónico: revistadearquitectura@ucatolica.edu.co cifar@ucatolica.edu.co

Página WEB: www.ucatolica.edu.co vínculo Revistas científicas

http://publicaciones.ucatolica.edu.co revistas-cientificas http://editorial.ucatolica.edu.co/ojsucatolica/revistas ucatolica/index.php/RevArq 
